\title{
Physiological changes in ageing muscles
}

\author{
M. J. CAMPBEll, A. J. McCOMAS, AND F. PETITO \\ From the Regional Neurological Centre, Newcastle General Hospital, Newcastle upon Tyne, \\ and McMaster University Medical Centre (Neurology), Hamilton 16, Ontario, Canada
}

\begin{abstract}
SUMMARY Physiological studies have been made of extensor digitorum brevis muscles in 28 healthy subjects aged between 60 and 96. Within this elderly population there was evidence of muscle wasting and weakness. These changes were shown to result from a loss of functioning motor units. The surviving motor units were often enlarged and tended to have relatively slow twitches. In some subjects the maximum impulse conduction velocities were reduced in motor nerves; there was evidence that slowing of impulse conduction could be especially marked in distal regions of axons. The findings are considered to indicate the presence of motoneurone dysfunction in old age.
\end{abstract}

It is well established that there is a decline in muscular performance with advancing age. For example, Burke, Tuttle, Thompson, Janney, and Weber (1953) found that maximum grip strength fell to almost half between the ages of 25 and 79 years. Associated with such findings is the common observation of muscle wasting in the elderly, particularly of proximal limb muscles but also clearly evident in the small muscles of the hand. Undoubtedly many extraneous factors may contribute to neuromuscular disease in the elderly, of which the most important are probably malnutrition, disuse, circulatory impairment, and occult carcinoma. In the present study we have been largely able to exclude these factors by selecting only healthy and active subjects. A further feature of the investigation is that recently described techniques have been employed to estimate the isometric twitch tension and also the number and sizes of motor units in a muscle (the extensor digitorum brevis; see McComas, Fawcett, Campbell, and Sica, 1971a; and Sica and McComas, 1971).

Perhaps the most interesting and significant finding in the present study has been a progressive fall in the number of functioning motor units beyond the age of 60 . The nature of this reduction, and its consequence for the surviving motoneurones, will be discussed. A preliminary account of this work has been presented elsewhere (Campbell and McComas, 1970).

\section{METHODS}

SUBJECTS Seventeen men and 11 women, aged between 60 and 96 years were studied (mean age $\sigma$ $79 \cdot 4, \mathrm{SD} \pm 12 \cdot 2$ years). All the subjects were judged to be in good physical condition for their age and had led active lives at home before admission to hospital. In some cases, admission had been made on social grounds and was for a short period only, while in others it had been required for the treatment of minor, non-neurological, ailments. Seven of the men were about to undergo prostatectomy but in all of them the blood urea levels were within normal limits. Each subject was given a careful medical examination and particular attention was paid to the vasculature of the leg under study. No patient was accepted if there was cutaneous evidence of circulatory impairment or if neither the dorsalis pedis or medial plantar arterial pulses could be felt in the same leg. A total of seventy-two subjects of both sexes between the ages of 3 and 58 years served as controls. Unfortunately it proved especially difficult to obtain an adequately sized population of control subjects aged 40 to 60 years. For this reason we have included observations on the estimated numbers of motor units in 10 patients who had previously had hemiplegias but in whom the investigated leg showed no neurological abnormality on careful clinical examination. Although the results from these patients did not differ significantly from those in completely normal controls, the values have been distinguished in Fig. 2. No other observations from the hemiplegic patients have been included in this study. 
ELECTROPHYSIOLOGICAL INVESTIGATIONS The number of motor units in the extensor digitorum brevis (EDB) muscle was estimated by the method of McComas et al. (1971a) and compared with the isometric twitch tension of the extensor hallucis brevis muscle (EHB) (most medial subdivision of EDB: see Sica and McComas, 1971). A collision technique (Thomas, Sears, and Gilliatt, 1959) was used to compare impulse propagation in the fastest and slowest conducting fibres of the deep peroneal nerve. Electromyography was also performed in EDB muscles of 13 elderly and 13 adult control subjects using a concentric needle electrode (Disa type 9013K0511) and an amplifier with a passband extending from $2 \mathrm{~Hz}$ to $10 \mathrm{kHz}$. In each muscle three sites, separated from each other by at least $1 \mathrm{~cm}$ in the transverse axis of the muscle, were explored during slight effort until twenty or more distinctive muscle action potentials had been analysed for amplitude, duration and configuration. In patients with severe denervation it was only possible to study relatively small numbers of units.

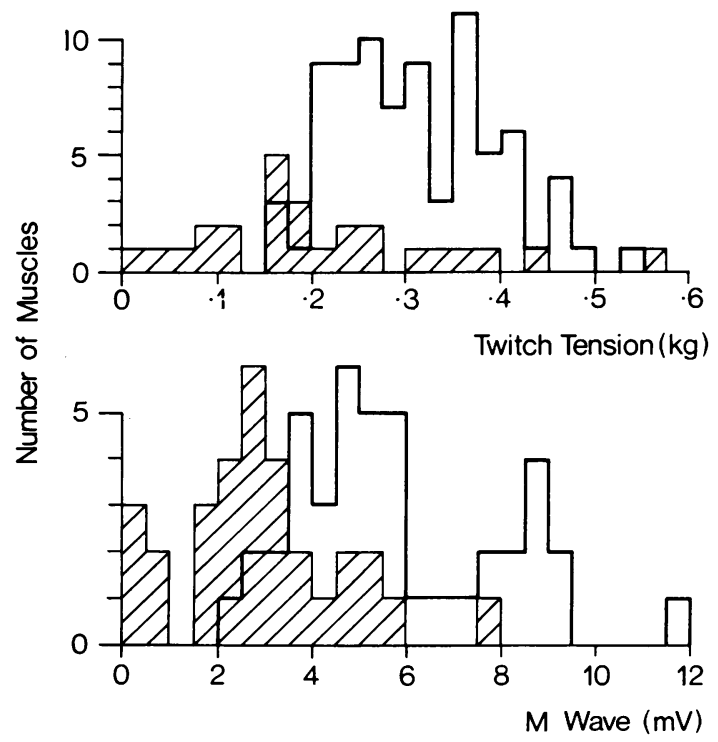

FIG. 1. Upper. Comparison of twitch tensions in 26 legs of elderly subjects and in 81 legs of controls (means $210 \pm 131 \mathrm{~g}$ and $310 \pm 88 \mathrm{~g}$ respectively; $\boldsymbol{P}<0.001)$.

Lower. Comparison of $M$ wave amplitudes in 34 legs of elderly subjects and in 43 legs of controls (means $2 \cdot 7 \pm 1.7 \mathrm{mV}$ and $5 \cdot 7 \pm 2 \cdot 1 \mathrm{mV}$ respectively; $P<0.001)$. Observations in control subjects shown by open columns and in elderly subjects by hatched columns.
STATISTICAL TREATMENT Unless stated otherwise, all means have been expressed with their standard deviations; the significance of a difference between mean values was calculated using Student's $t$ test.

\section{RESULTS}

GROSS EVIDENCE OF MUSCLE DYSFUNCTION IN THE ELDERLY Two simple methods may be used to assess the functional status of a muscle and both depend on the total cross-sectional area of the activated muscle fibres; they are the measurements of $M$ wave amplitude and of maximal twitch tension. It can be seen from Fig. 1 that these parameters were usually, but not invariably, reduced in elderly subjects in comparison with controls. This diminution was most evident for the $M$ wave, the mean results for the elderly and control subjects being $2.7 \pm 1.7 \mathrm{mV}$ and 5.7 $\pm 2 \cdot 1 \mathrm{mV}$ respectively $(\mathrm{P}<0.001)$. It has already been shown that an ageing EHB muscle is able to develop maximal twitch tension when the initial length of the muscle is only slightly increased (Sica and McComas, 1971). This finding is in contrast with the situation in a young person, in whom the EHB twitch tension may not be maximal even when the great toe is fully plantarflexed. This difference in the lengthtension relationship between elderly and young subjects would tend to obscure the full loss of force which occurs with age. Nevertheless, in the present study the mean twitch tensions in the controls and elderly still differed significantly $(310 \pm 88 \mathrm{~g}$ and $210 \pm 131 \mathrm{~g}$ respectively; $\mathrm{P}<0 \cdot 001)$.

NUMBERS OF MOTOR UNITS IN THE ELDERLY In 66 control subjects the mean number of motor units was $197 \pm 58$ and there was no evidence of any decline between the ages of 3 and 58 years ( $r=-0.04$; see also McComas et al., 1971). Beyond the age of 60 years, however, many subjects exhibited a loss of functioning units and this reduction became more apparent with advancing age. It is clear from Fig. 2 that within the elderly population there was considerable variation in residual innervation; for example one 83 year old lady had no functioning EDB units in one leg and only one in the other. At the other extreme a sprightly 93 year old lady was estimated to have about 112 units in one EDB 


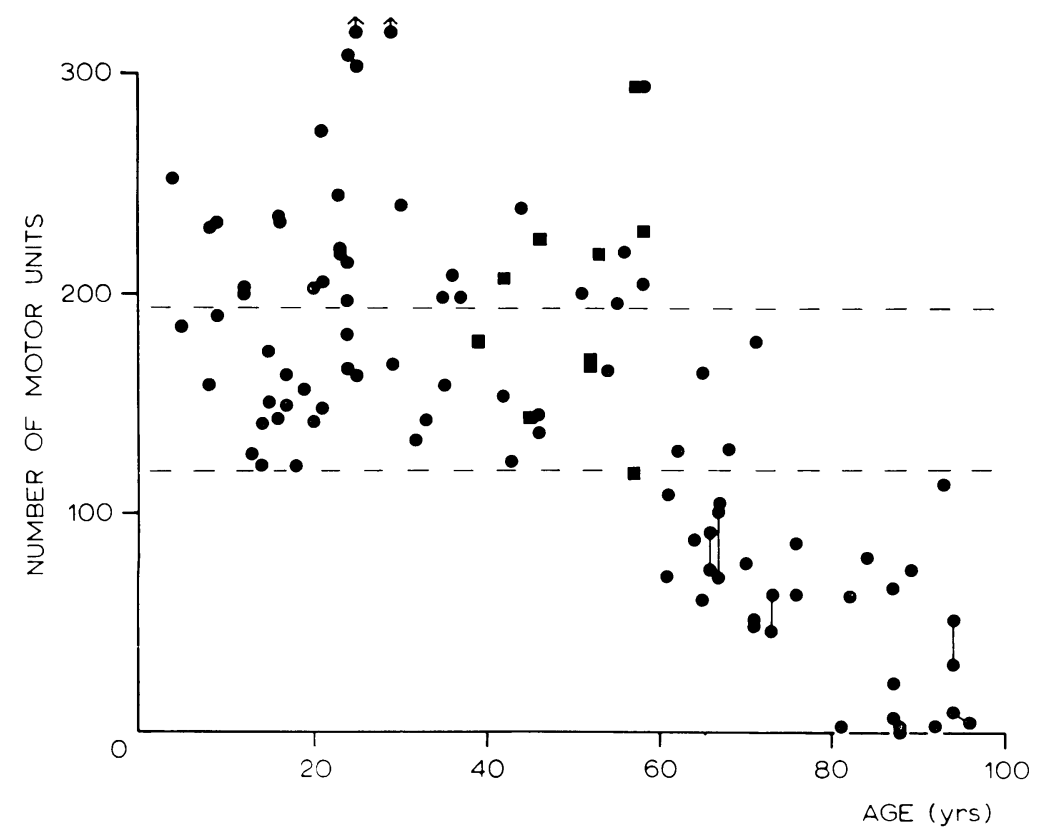

FIG. 2. Numbers of functioning EDB motor units in 94 subjects aged between 3 and 96 years (101 legs altogether). Vertical lines link results in both legs of same subject. Squares denote calues obtained in 'normal' legs of 10 hemiplegic patients (see methods). Upper interrupted horizontal line shows mean number of units in control subjects aged 3-58 years (197 units); lower interrupted line indicates smallest value in same subjects (121 units).

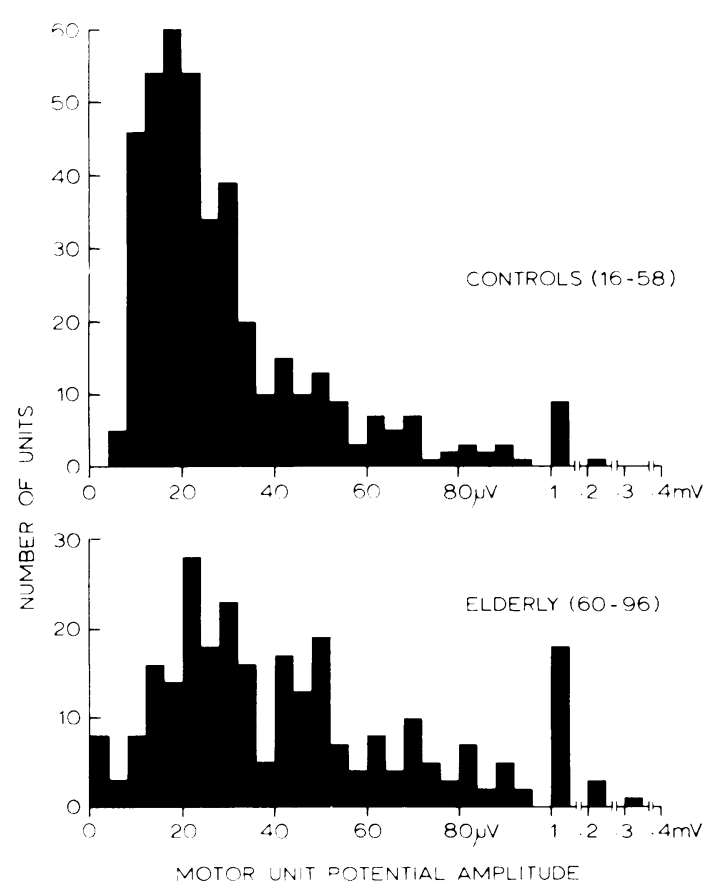

FIG. 3. Amplitudes of 268 motor unit potentials in elderly subjects (mean 47.6 $\pm 43 \cdot 2 \mu \mathrm{V}$ ) and in 415 potentials of controls aged 17-58 years (mean $29.9 \pm 25.5 \mu \mathrm{V} ; P<0.001)$. All measurements made from recordings with surface electrodes. muscle. In addition to the subject already men tioned, a further five had EDB muscles investi gated in both legs; the paired estimates were 100 and 70,90 and 73,61 and 45,51 and 31 , and 21 and 6 units respectively.

PROPERTIES OF SURVIVING MOTOR UNITS The motor units remaining in the elderly were investigated in several ways. In Fig. 3 the amplitudes of the individual motor unit action potentials have been compared with those of the control population. Although there is considerable overlap between the two populations. many of the potentials in the elderly were greater than $100 \mu \mathrm{V}$ and the mean value, $47 \cdot 6 \pm 43 \cdot 2 \mu \mathrm{V}$. differed significantly from that of the controls $(29 \cdot 9 \pm 25 \cdot 5 \mu \mathrm{V}$; $\mathrm{P}<0.001)$. This result indicated that the crosssectional area of the surviving motor units had increased either through adoption of denervated fibres or by fibre hypertrophy or by both mechanisms. In this study, only six single unit twitches were recorded in the elderly but one of these had a tension of $62 \mathrm{~g}$ which was considerably larger than the upper limit of the control range $(14 \mathrm{~g}$, Sica and McComas, 1971).

In one patient, a 92 year old man, it was possible to compare the mechanical and electrical 

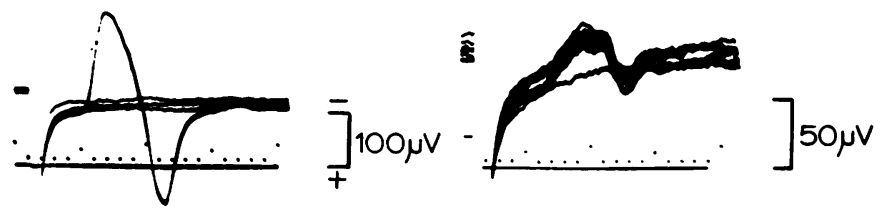
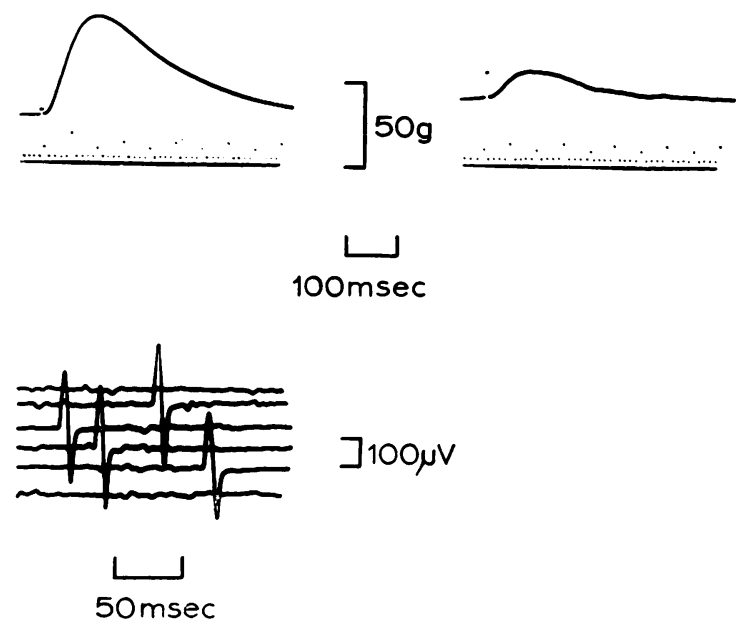

properties of the sole surviving unit. In Fig. 4 it can be seen that an all-or-nothing response was obtained on indirect stimulation and the voluntarily-induced electromyogram confirmed that only a single unit was present. This unit had a potential amplitude of $340 \mu \mathrm{V}$, slightly greater than any found in the control population of 415 units; the large twitch tension of this unit has already been referred to ( $62 \mathrm{~g}$; see above). When the same muscle was examined five weeks later a single unit response was obtained once more but was now much smaller, the potential amplitude and twitch tension being $32 \mu \mathrm{V}$ and $5 \mathrm{~g}$ respectively (Fig. 4). Further examination at seven and 11 weeks after the initial one disclosed no further change. It was conceivable that the unit studied at the first examination had ceased to function and that a second nerve fibre had regenerated. On the other hand, certain observations suggested that all the responses had been obtained

FIG. 4. Studies on the sole surviving motor unit in the EDB muscle of a 92 year old man. Left hand column shows observations made at initial examination; all-ornothing responses on indirect stimulation (top), isometric twitch (middle) and electromyogram during maximal effort (bottom). Right hand column displays results obtained five weeks later, showing much smaller electrical and mechanical responses. Electrical recordings made with surface electrodes. See text. from the same motor unit and that the territory of this unit had been reduced by impulse blockage in a major branch of the motor axon concerned. In the first place, it was noted that the number of units remained constant, whereas if nerve fibre regeneration was occurring to any extent, the number of functioning units might have been expected to vary. Secondly, the motor unit potential amplitude did not increase in size after the second examination, suggesting that the numbers and sizes of the innervated fibres remained the same. A regenerated motor axon might have continued to adopt denervated fibres, while newly innervated muscle fibres would have increased their diameters over a period of time. Finally, on all four occasions the end-plate zone of the remaining unit was situated in the most medial part (EHB) of EDB. If, in fact, all the observations were made on the same unit, then it is possible that they signalled 


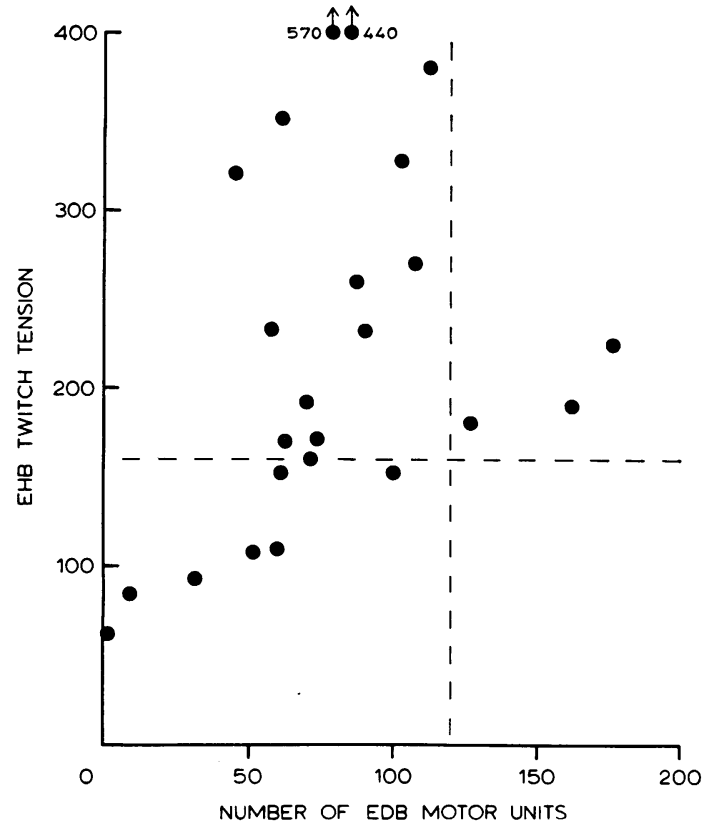

FIG. 5. Relationship between EHB twitch tensions and numbers of surviving EDB motor units in 24 legs of elderly subjects. Interrupted lines indicate lower limits of respective observations in controls.

an early stage of a 'dying back' process (Cavanagh, 1964). In this connection it is of interest that the latency of the response to indirect stimulation increased by rather more than $1 \mathrm{msec}$ before the second examination (Fig. 4).

In Fig. 5 the mechanical efficiency of the units surviving in this and other subjects have been displayed by comparing the maximum EHB twitch tensions with the numbers of EDB units remaining. It can be seen that the observed tensions are greater than those which would have been obtained had no compensatory change taken place in the surviving motor units. Although part of this improvement will have been a consequence of the altered length-tension curve in the elderly, it is probable that collateral reinnervation and muscle fibre hypertrophy were the major factors.

The isometric twitch recordings were of interest in another respect, for they yielded information about the time courses of contraction and relaxation in the activated fibres. It was found that both phases of the twitch were usually

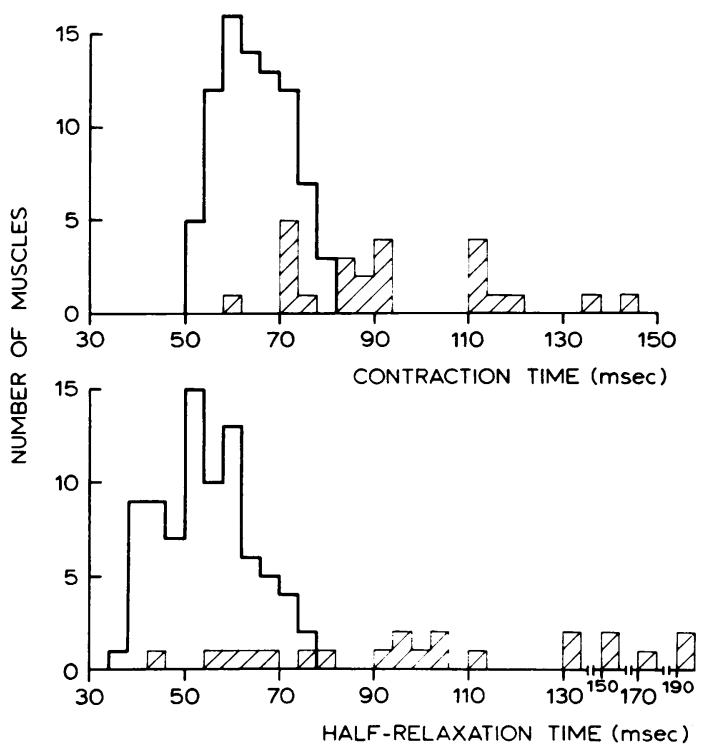

FIG. 6. Upper. Contraction times of isometric twitches in 24 legs of elderly subjects (hatched columns) and in 79 legs of controls (open columns); respective mean values were $93 \pm 22$ msec and $64 \pm 7.0 \mathrm{msec}(P=<0.001)$. Lower. Comparison of half-relaxation times in elderly and control populations; means were $109 \pm 45$ and $53 \pm 9.6 \mathrm{msec}$ re spectively $(P<0.001)$.

prolonged in the elderly (Fig. 7); the mean contraction and half-relaxation times $(93 \pm 22$ and $109 \pm 45 \mathrm{msec}$ respectively) differed significantly from corresponding values in the controls $(64 \pm 7$ and $53 \pm 10 \mathrm{msec} ; \mathrm{P}<0.001$ in each case).

OTHER STUDIES In 25 elderly subjects measurements were made of impulse velocity in the fastest conducting nerve fibres and of the latencies of the evoked EDB responses following indirect stimulation at the ankle(terminal latency). From Fig. 7 it can be seen that all the latter values fell within the normal range (up to 5.0 msec), and the mean values determined for the elderly and control populations were identical $(4.0 \mathrm{msec})$. In contrast the mean (maximal) motor nerve impulse conduction velocity was significantly lower in the elderly $(44 \cdot 2 \pm 4 \cdot 1$ $\mathrm{m} / \mathrm{sec}$; control mean $48 \cdot 1 \pm 3.9 \mathrm{~m} / \mathrm{sec} ; \mathrm{P}<0.001)$. When the conduction velocities were considered individually, five subjects had values which fell 

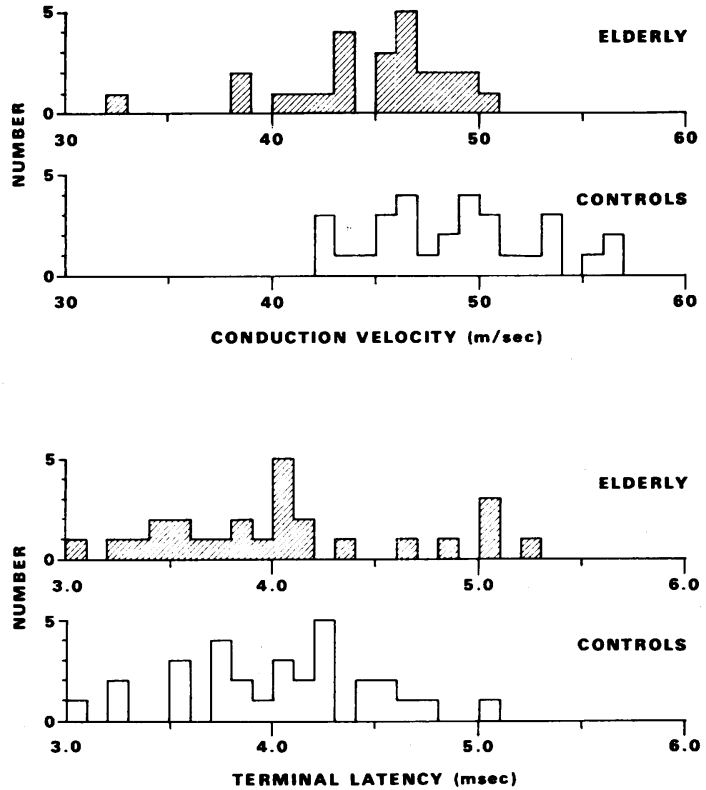

FIG. 7. Upper. Maximal impulse conduction velocities in deep peroneal nerves of 25 legs in elderly subjects (hatched columns) and in 30 legs of controls (open columns); respective mean values were 44.2 $\pm 4.1 \mathrm{~m} / \mathrm{sec}$ and $48.1 \pm 3.9 \mathrm{~m} / \mathrm{sec}(P<0.001)$. Lower. Comparison of terminal latencies (see text) in elderly and control populations; means were $4.0 \mathrm{msec}$ in each case.

outside the control range of $42-60 \mathrm{~m} / \mathrm{sec}$. In this laboratory velocities lower than $40 \mathrm{~m} / \mathrm{sec}$ are regarded as definitely abnormal in subjects below the age of 60 . In the elderly subject with the lowest velocity $(32 \mathrm{~m} / \mathrm{sec})$ only a single motor axon remained. In 11 of the elderly subjects determinations were made of the latencies of the muscle responses mediated by the least excitable nerve fibres after stimulation at the knee, using the technique of Thomas et al. (1959). The least excitable fibres would be expected to include those with the lowest conduction velocities (Erlanger and Gasser, 1937). However, it is known that other factors, such as the relative accessibility of the fibres to the stimulating current, are also important in determining the thresholds of the fibres when surface electrodes are employed (Bergmans, 1970; McComas et al., 1971a). In our experience the difference between the latencies of the muscle responses evoked by the least excitable and most excitable fibres does not exceed $4.0 \mathrm{msec}$ in normal subjects. In three of the 11 subjects tested values larger than this were obtained $(23.0,12.9$, and $12.0 \mathrm{msec})$. In these three instances the responses evoked by the slowest conducting fibres were sufficiently delayed to permit their identification after maximal stimulation of the nerve at the ankle. In these three subjects it appeared that, although impulse conduction was slowed in the affected fibres below the ankle, it was normal in the segment of nerve between the knee and ankle.

\section{TABLE}

MEAN MUSCLE ACTION POTENTIAL PARAMETERS IN CONTROLS AND ELDERLY SUBJECTS

\begin{tabular}{lccc}
\hline & $\begin{array}{c}\text { Amplitude } \\
(\mu \mathrm{V})\end{array}$ & $\begin{array}{c}\text { Duration } \\
(\text { msec })\end{array}$ & $\begin{array}{c}\text { Phases } \\
(\text { no. })\end{array}$ \\
\hline Controls (193) & $878 \pm 907$ & $9 \cdot 1 \pm 3 \cdot 1$ & $2 \cdot 7 \pm 1.3$ \\
Elderly (146) & $739 \pm 874$ & $9.9 \pm 3.0$ & $2 \cdot 7 \pm 1.4$ \\
P & $>0.1$ & 0.01 & $>0.9$ \\
\hline
\end{tabular}

Numbers of potentials measured are given in parentheses in left hand column.

In the early part of the study quantitative electromyography was performed in 13 elderly subjects and in the same number of controls. This investigation was discontinued when it became clear that information about motor unit function could be obtained more easily and precisely from the unit estimating technique of McComas et al. (1971a). Of the 146 muscle action potentials investigated altogether in the elderly population, the mean durations, amplitudes and numbers of phases have been given in the Table. Although no significant change was noted in the last two parameters, there was a small but significant increase in the mean action potential duration in the elderly, confirming previous observations (Petersén and Kugelberg, 1949; Sacco, Buchthal, and Rosenfalck, 1962). If, however, the results were considered for individual subjects rather than for the whole population, then in only one of the elderly subjects with more than 50 units remaining was the electromyogram abnormal. In this subject a high incidence of 'myopathic' potentials was detected 
in one region of the EDB muscle. In spite of the loss of functioning motor units in many elderly subjects, fibrillation potentials were not a feature of the present study.

\section{DISCUSSION}

Of all the causes of muscle wasting, ageing is by far the commonest and it is therefore surprising that so little attention has been paid to its mechanism. Moreover, in the few studies available, opinion appears to be equally divided between a myopathic process (Betourne, 1953; Verzar, 1959; Serratrice, Roux, and Aquaron, 1968) and a neuropathic one (Lhermitte, 1901; Rubinstein, 1960; Tomlinson, Walton, and Rebeiz, 1969). It is probable that this conflict reflects the difficulties inherent in a study of this kind. Old people are prone to debilitating illness which, as in the case of diabetes mellitus, may sometimes remain unsuspected in life. The illness itself may necessitate bed rest or other forms of immobilization and these in turn may provoke disuse atrophy. Malnutrition is also common in the elderly and finally there remains the contribution of vascular insufficiency to myoneural degeneration. For these reasons it is uncertain what significance may be attached to studies of post-mortem material from patients who had suffered from various disorders and in whom the vascular and neurological status of the limbs was unknown before the terminal illness or accident. Furthermore, in those studies employing histological methods, the interpretation of muscle fibre architecture remains an indirect means of assessing motor nerve function and can give no indication of the numbers and sizes of surviving motor units. Attempts to recognize myopathic lesions in senile muscles are also questionable, since it is now accepted that 'myopathic' features may occur in any longstanding neuropathic process (for example, see Mumenthaler, 1970). Although histological examinations of motoneurones, ventral roots, peripheral nerves, or neuromuscular junctions provide more acceptable approaches to the problem of ageing, it is possible that the results of such studies may underestimate functional deficits (see McComas, Sica, and Campbell, 1971b).

In the present study an attempt has been made to exclude these factors by restricting the study to elderly people who were in good health and leading active lives. In addition, a relatively direct method has been employed to estimate the numbers and sizes of motor units. The choice of EDB as a suitable muscle for this kind of $\frac{\rho}{\square}$ investigation might be questioned, since changes suggestive of denervation were found in a recent post-mortem study of this muscle in $\overrightarrow{\bar{B}}$ 'controls' (Jennekens, Tomlinson, and Walton, $\overrightarrow{0}$ 1971). While acknowledging that some degree of denervation might occur in apparently healthy subjects, we had previously pointed out that such a process was unlikely to involve a significant proportion of the motor unit population (McComas et al., 1971a). It is therefore felt that the present approach is not only justifiable, but that it offers real advantages over methods formerly employed to study the cause of muscle wasting in the elderly. Although this study has been confined to EDB, it is reasonable to assume that the abnormalities detected in this muscle are qualitatively similar to those occurring in other muscles in any generalized neuromuscular disorder. So far as the intensity of the disease proe cess is concerned, it is probable that the EDE muscle will sometimes show particularly striking changes because of the increased susceptibility of long axons to degeneration of the "dying-back" type (Cavanagh, 1964).

In the present study the results have been unequivocal; the most important factor contributing to wasting and weakness of ageing muscles is a reduction in the number of functional motor units. The study has also shown that the severity of the denervating process varies considerably among individuals but that it does not usually commence before the age of sixty years. In certain other studies of peripheral nerve either the density or the total number of nerve fibres have been counted (Swallow, 1966; O'Sullivan and Swallow, 1968). Although these last observations were made on cutaneous nerves, they have also revealed a loss of nerve fibres which was particularly marked in and beyond the seventh decade. Other authors have dissected single nerve fibres and have shown that abnormalities of myelination, suggestive of degeneration and regeneration, are more common in elderly subjects (Vizoso, 1950; Lascelles and Thomas, 1966; Ochoa and Mair, 1969; Arnold and Harriman 1970). However, the physiological nature of the 
present investigation has demonstrated that the true extent of the loss of neural function is far greater than that suggested by morphological studies of peripheral nerve (see above), ventral root fibres (Corbin and Gardner, 1937) and motoneurones (Gardner, 1940). The present findings are in contrast with the situation in the 30 months old rat, in which the careful studies of Gutmann and Hanzlíková (1966) have not shown a loss of motor axons. In these animals miniature end-plate potentials persist although their frequency of discharge is reduced (Gutmann, Hanzlíková, and Vyskocil, 1971). These last authors regard senile muscle atrophy as a specific entity with both pre- and post-synaptic elements. In man, however, we have shown that the atrophic process does not select neuromuscular functions randomly, since entire motor units may cease to function. This finding indicates that not only is the underlying mechanism one of denervation but that the primary lesion is situated centrally, within the main axon or motoneurone (see below). In the present study it has also been possible to estimate the rate of this process. From inspection of Fig. 2 (see Results) the rate of motor unit loss is such that denervation would have usually been complete in EDB had the investigated subjects lived to the age of 90 years. The true rate in the general population will have been greater than this, for, at ages beyond the mean life expectancy, the population under study becomes increasingly artificial. Thus, it is reasonable to suppose that those subjects in whom the denervating process is most severe would, because of their weakness, be more vulnerable to intercurrent illness and would not survive for study.

The present investigation also throws light on two properties of the surviving motoneurones. Firstly, from the muscle contraction experiments, it would appear that most motoneurones innervate muscle fibres of the slow-twitch type. A reduced speed of contraction was also found in aged rats by Gutman et al. (1971). Whether the ageing process involves fast-twitch units preferentially or whether the slowing results from excessive activity in the surviving innervated muscle fibres cannot be determined (see Salmons and Vrbova, 1967; Olson and Swett, 1969). A second property of the surviving motoneurones emerges from the measurements of motor unit potential amplitude and of twitch tension. These indicate that, even in the elderly, the residual motoneurones can participate in compensatory changes, either by sustaining hypertrophied muscle fibres or by adopting denervated fibres. Although these responses are not as marked as those of motoneurones in younger patients with longstanding denervation (McComas, Sica, Campbell, and Upton, 1971c) they would still serve to reduce loss of strength in an elderly subject. A third type of compensatory neural response, recently investigated in detail by Tuffery (1971), would also be expected to occur though there is at present no electrophysiological method of assessing its prevalence in man. In this process ageing motoneurones send supplementary axonal sprouts to reinforce the existing innervations of muscle fibres.

Finally, the nature of the pathological process responsible for the loss of functioning units remains to be considered. The only observations in the present study relevant to this problem are the measurements of impulse propagation velocity. The finding of a moderate reduction in the maximum velocities in the elderly confirmed earlier observations made on motor axons by Norris, Shock, and Wagman (1953) and on sensory axons by Downie and Newell (1961) and Buchthal and Rosenfalck (1966). The very marked slowing of impulse conduction in distal regions of some motor fibres would suggest that these fibres had undergone segmental demyelination and could indicate a primary dysfunction of Schwann cells. Recently, however, it has become recognized that Schwann cell dysfunction, like axonal degeneration, may result from a lesion of the perikaryon (for example, Dyck, Johnson, Lambert, and O'Brien, 1971). In the absence of evidence to the contrary, our present hypothesis is that the denervating process which we have demonstrated in the elderly arises from motoneurone dysfunction, with or without recognizable morphological abnormality (cf. McComas et al., 1971b).

Financial support was received from the Medical Research Councils of Great Britain and Canada. We are grateful to Mrs. B. MacLean for secretarial services and to Mr. T. Blogg for technical assistance. 


\section{REFERENCES}

Arnold, N., and Harriman, D. G. F. (1970). The incidence of abnormality in control human peripheral nerves studied by single axon dissection. Journal of Neurology, Neurosurgery, and Psychiatry, 33, 55-61.

Bergmans, J. (1970). The Physiology of Single Human Nerve Fibres. Vander: Louvain.

Betourne, C. (1953). Sénescence et arthrose. Revue du Praticien, 3, 2143-2146.

Buchthal, F., and Rosenfalck, A. (1966). Evoked action potentials and conduction velocity in human sensory nerves. Brain Research, 3, 1-122. Special Issue.

Burke, W. E., Tuttle, W. W., Thompson, C. W., Janney, C. D., and Weber, R. J. (1953). The relation of grip strength and grip-strength endurance to age. Journal of Applied Physiology, 5, 628-630.

Campbell, M. J., and McComas, A. J. (1970). The effects of ageing on muscle function. In Abstracts of 5th Symposium on Current Research on Muscular Dystrophy and Related Diseases. London, 1970. Communications. Abstract No. 6. Muscular Dystrophy Group of Great Britain: London.

Cavanagh, J. B. (1964). Peripheral nerve changes in orthocresyl phosphate poisoning in the cat. Journal of Pathology and Bacteriology, 87, 365-383.

Corbin, K. B., and Gardner, E. D. (1937). Decrease in number of myelinated fibres in human spinal roots with age. Anatomical Record, 68, 63-74.

Downie, A. W., and Newell, D. J. (1961). Sensory nerve conduction in patients with diabetes mellitus and controls. Neurology (Minneapolis), 11, 876-882.

Dyck, P. J., Johnson, W. J., Lambert, E. H., and O'Brien, P. C. (1971). Segmental demyelination secondary to axonal degeneration in uremic neuropathy. Mayo Clinic Proceedings, 46, 400-431.

Erlanger, J., and Gasser, H. S. (1937). Electrical Signs of Nervous Activity. University of Pennsylvania Press: Philadelphia.

Gardner, E. D. (1940). Decrease in human neurones with age. Anatomical Record, 77, 529-536.

Gutmann, E., and Hanzliková, V. (1966). Motor unit in old age. Nature, 209, 921-922.

Gutmann, E., Hanzlíková, V., and Vyskočil, F. (1971). Age changes in cross striated muscle of the rat. Journal of Physiology, 216, 331-343.

Jennekens, F. G. I., Tomlinson, B. E., and Walton, J. N. (1971). Data on the distribution of fibre types in five human limb muscles. An autopsy study. Journal of the Neurological Sciences, 14, 245-257.

Lascelles, R. G., and Thomas, P. K. (1966). Changes due to age in internodal length in the sural nerve in man. Journal of Neurology, Neurosurgery, and Psychiatry, 29, 40-44.

Lhermitte, J.-J. (1907). Étude sur les Paraplégies des Vieillards. Thèse de Médicine, 1906-1907. No. 160. Paris.

McComas, A. J., Fawcett, P. R. W., Campbell, M. J., and Sica, R. E. P. (1971a). Electrophysiological estimation of the number of motor units within a human muscle. Journal of Neurology, Neurosurgery, and Psychiatry, 34, 121-131.
McComas, A. J., Sica, R. E. P., and Campbell, M. J. (1971b), 'Sick' motoneurones. A unifying concept of muscle disease. Lancet, 1, 321-325.

McComas, A. J., Sica, R. E. P., Campbell, M. J., and Upton, A. R. M. (1971c). Functional compensation in partially denervated muscles. Journal of Neurology, Neurosurgery, and Psychiatry, 34, 453-460.

Mumenthaler, M. (1970). Myopathy in neuropathy. In Muscle Diseases. Proceedings of an International Congress, Milan, 1969, pp. 585-598. Edited by J. N. Walton, N. Canal, and G. Scarlato. International Congress Series No. 199. Excerpta Medica: Amsterdam.

Norris, A. H., Shock, N. W., and Wagman, I. H. (1953). Age changes in the maximum conduction velocity of motor fibers of human ulnar nerves. Journal of Applied Physiology, $5,589-593$.

Ochoa, J., and Mair, W. G. P. (1969). The normal sural nerve in man. 2. Changes in the axons and Schwann cells due to ageing. Acta Neuropathologica (Berlin), 13, 217-239.

Olson, C. B., and Swett, C. P., Jr. (1969). Speed of contraction of skeletal muscle. The effect of hypoactivity and hyperactivity. Archives of Neurology (Chicago), 20, 263270.

O'Sullivan, D. J., and Swallow, M. (1968). The fibre size and content of the radial and sural nerves. Journal of Neurology, Neurosurgery, and Psychiatry. 31, 464-470.

Petersén, I., and Kugelberg, E. (1949). Duration and form of i action potential in the normal human muscle. Journal of Neurology, Neurosurgery, and Psychiatry, 12, 124-128.

Rubinstein, L. J. (1960). Aging changes in muscle. In the Structure and Function of Muscle. Vol. 3, pp. 209-226. Edited by G. H. Bourne. Academic Press: New York. Sacco, G., Buchthal, F., and Rosenfalck, P. (1962). Moton unit potentials at different ages. Archives of Neurolog 8 (Chicago), 6, 366-373.

Serratrice, G., Roux, H., and Aquaron, R. (1968). Proxima muscular weakness in elderly subjects. Report of 12 casesJournal of the Neurological Sciences, 7, 275-299.

Sica, R. E. P., and McComas, A. J. (1971). Fast and slow twitch units in a human muscle. Journal of Neurology, Neurosurgery, and Psychiatry, 34, 113-120.

Swallow, M. (1966). Fibre size and content of the anterior tibial nerve of the foot. Journal of Neurology, Neurosurgery, and Psychiatry, 29, 205-213.

Thomas, P. K., Sears, T. A., and Gilliatt, R. W. (1959). The range of conduction velocity in normal motor nerve fibres to the small muscles of the hand and foot. Journal of Neurology, Neurosurgery, and Psychiatry, 22, 175-181.

Tomlinson, B. E., Walton, J. N., and Rebeiz, J. J. (1969). The effects of ageing and of cachexia upon skeletal muscle. A histopathological study. Journal of the Neurological Sciences, 9, 321-346.

Tuffery, A. R. (1971). Growth and degeneration of motor end-plates in normal cat hind limb muscles. Journal of Anatomy, 110, 221-247.

Verzar, F. (1959). Muscular dystrophy in old age. Gerontologia Clinica (Basel), 1, 41-51.

Vizoso, A. D. (1950). The relationship between internodal length and growth in human nerves. Journal of Anatomy, 84, 342-353. 